\title{
Municipality screening of citizens with suspicion of chronic obstructive pulmonary disease
}

This article was published in the following Dove Press journal:

International Journal of COPD

31 January 2012

Number of times this article has been viewed

\author{
Tina Riegels-Jakobsen' \\ Malene Skouboe' \\ Jens Dollerup ${ }^{2}$ \\ Christian Buus Andersen² \\ Louise Barkan Staal' \\ Rolf BH Jakobsen' \\ Peter Bo Poulsen ${ }^{2}$ \\ 'Department of Health Prevention \\ and Promotion, Municipality \\ of Esbjerg, Esbjerg, ${ }^{2}$ Medical \\ and Access, Pfizer Denmark, \\ Ballerup, Denmark
}

\begin{abstract}
Up to 436,000 adult Danes suffer from chronic obstructive pulmonary disease (COPD), with only one third diagnosed at this time. The Danish National Board of Health recommends early detection of COPD, focusing on smokers/ex-smokers over 35 years of age with at least one lung symptom. A governmental prevention committee has suggested that the municipalities, in addition to general practice, should be a potential arena responsible for early detection of COPD. We undertook a pilot study to investigate the feasibility and effectiveness of early detection of COPD in municipalities following the recommendations of the Danish National Board of Health.
\end{abstract}

Methods: The Municipality of Esbjerg offered spirometry to Danish citizens at risk of COPD without a previous diagnosis of the disease, following the National Board of Health's recommendations. Citizens with evidence of airway obstruction (forced expiratory volume in one second $\left[\mathrm{FEV}_{1}\right]$ /forced vital capacity $[\mathrm{FVC}]<70 \%$ ) were advised to visit their general practitioner for diagnosis. These citizens were followed up by telephone interview 3 months later.

Results: Of 152 citizens sampled ( $50 \%$ females, mean age 58 years, $51 \%$ smokers) $51.3 \%$ had evidence of airway obstruction, with $87 \%$ being mild to moderate in terms of severity. Seven of ten citizens ( $71 \%$ ) then visited their general practitioner, with $85 \%$ of these being diagnosed with COPD. The number of smokers embarking on smoking cessation or quitting smoking increased following COPD screening, with the highest frequency in participants with evidence of airway obstruction.

Conclusion: In addition to early detection of COPD in general practice, early detection of airway obstruction in defined risk populations in Danish municipalities seems feasible and effective for identifying new patients with COPD. However, additional research is needed in larger samples to confirm the results of the present study.

Keywords: chronic obstructive pulmonary disease, screening, spirometry, smoking cessation

\section{Background}

Chronic obstructive pulmonary disease (COPD) is characterized by chronic airflow limitation and a range of pathological changes in the lung, significant extrapulmonary effects, and important comorbidities. ${ }^{1}$ A recent study suggests that 300,000-436,000 Danes (7\%-10\% of the adult population) suffer from COPD. ${ }^{2}$ However, only approximately 150,000 of these citizens appear to have been diagnosed at this time. ${ }^{3}$

A total of 21,386 Danes were hospitalized and 3478 deaths occurred in 2009 as a result of COPD. ${ }^{4,5}$ Illustrating the burden of the disease, in 2002, each COPD patient incurred an extra $€ 4400$ per year in health care costs compared with patients without the disease. ${ }^{6}$ Health care costs increase with stage of COPD severity. ${ }^{7-9}$ To reduce
Correspondence: Peter Bo Poulsen Customer Development Manager, Pfizer Denmark Aps, Medical and Access, Lautrupvang 8, DK-2750 Ballerup, Denmark

Tel +454420 I 21 I

Fax +454420 II I 4

Email peterbo.poulsen@pfizer.com 
costs, loss of quality of life, and premature death, early identification and diagnosis of COPD would be beneficial.

The risk factors for COPD are well known, with tobacco smoking accounting for $80 \%-90 \%$ of cases, and occupational and environmental risk factors for $10 \%-20 \%{ }^{1,10-12}$ According to current guidelines, management of COPD includes assessment and monitoring of the disease, reduction of risk factors to prevent progression, management of stable COPD, and management of exacerbations. ${ }^{1}$ For newly diagnosed and stable COPD patients, this implies initiation of smoking cessation for cigarette smokers, physical training, pharmacotherapy, patient education, dietary supervision, and psychosocial assistance. ${ }^{1,3}$ Rehabilitation of COPD patients takes place in hospitals, general practice, or at the municipality level. ${ }^{13-15}$ In Denmark, the National Board of Health recommends that patients undertake relevant prevention and rehabilitation initiatives. These initiatives include smoking cessation, preventing progression of loss of lung capacity, implementing optimal pharmacological therapy, and early detection of COPD, ie, screening. ${ }^{3}$

The Global Strategy for the Diagnosis, Management, and Prevention of COPD (GOLD) concludes that there is insufficient evidence at this time to recommend communitybased spirometric screening for COPD. ${ }^{1}$ Similarly, in 2008, the US Preventive Services Task Force advised against use of spirometry to screen for COPD in adults who do not recognize or report respiratory symptoms to a clinician. ${ }^{16}$ The American College of Physicians also concluded in 2007 that spirometry should not be used to screen for airflow obstruction in asymptomatic individuals, including those with risk factors for COPD. ${ }^{17}$

On the other hand, according to a Cochrane review, studies have shown the importance of early diagnosis and intervention of COPD to have an adequate effect. ${ }^{18}$ In a recent review of spirometry, Soriano et al stated that screening at all levels can be undertaken in community or health care settings, and that spirometry is the essential test for diagnosis and monitoring of COPD, although maintaining the quality of diagnostic spirometry is essential. ${ }^{19}$

In Denmark, the National Board of Health recommends that early detection of COPD should focus on patients older than 35 years and smokers/former smokers with one or more respiratory symptoms. ${ }^{3}$ A spirometric investigation should be offered to the population at risk as early as possible. People employed in high-risk occupations (eg, welders, bakers, dustmen) are also included in the recommendation.

Studies of early detection of COPD have primarily been carried out in general practice and hospital settings.
One example from primary care is a study by Ulrik et al who screened 3095 Danish patients using the same definition of risk as that used in our present study and identified $34.8 \%$ of patients with airway obstruction in accordance with GOLD. ${ }^{20}$ In another Danish study of walk-in spirometry carried out by regional hospitals in one region of Denmark in cooperation with The Danish Lung Association, markedly fewer patients ( $20 \%$ of 344 screened) were found to have COPD. ${ }^{21}$ However, in that study, spirometry examinations were only offered on one afternoon per month and were carried out by hospital staff. Internationally, using COPD screening in primary care practices in the UK and US, Tinkelman et al found that $18.9 \%$ of 818 smoking patients over 39 years of age had COPD. ${ }^{22}$ Similarly, in a Canadian study by Hill et al of 1459 patients in primary care, $20.7 \%$ were found to have COPD. ${ }^{23}$ Finally, Zielinski et al found that $24.3 \%$ of patients screening at 12 pulmonary outpatient clinics in Poland had COPD. ${ }^{24}$

In 2009, a government prevention committee in Denmark suggested that the municipalities could be one potential arena responsible for early detection of COPD, in addition to general practice. ${ }^{25}$ Adding to the knowledge base, it would therefore be of interest to investigate the feasibility and effectiveness of early detection of COPD in the municipality setting based on the recommendations issued by the Danish National Board of Health and the governmental prevention commission. The aim of the present study was to investigate the feasibility and effectiveness of early detection of airway obstruction and COPD at the municipality level in Denmark.

\section{Methods}

This pilot study was undertaken at the Healthcare Center of the Municipality of Esbjerg, which is the fifth largest municipality in Denmark and has approximately 115,000 inhabitants. The Healthcare Center recruited citizens at risk of COPD from local newspaper advertisements, from existing municipality courses and training, and from screening at market places. Recruitment for airway obstruction screening was based on self-referral. The study was designed and conducted as a noninterventional study, thus the screening and procedures followed current Danish guidelines. In accordance with the recommendations of the Danish National Board of Health, the inclusion criteria were:

- Age $>35$ years

- Smoker or ex-smoker

- Presence of at least one respiratory symptom, eg, dyspnea, cough, wheeze, phlegm

- Citizenship in the Municipality of Esbjerg

- No previous diagnosis of COPD. ${ }^{3}$ 
Individuals employed in high-risk occupations were not part of this screening. From September to December 2009, trained municipality health care personnel, ie, nurses and physiotherapists with experience in spirometry, offered spirometric investigations to citizens. The spirometry screening was done in accordance with American Thoracic Society/ European Respiratory Society guidelines but without bronchodilator testing for reversibility. ${ }^{26}$ The spirometer used was the Spirotrac IV (Model 6800, Ireland). Health care personnel performing and evaluating the spirometry were thoroughly trained, initially by a pulmonary specialist, ie, a hospital consultant with extensive experience in COPD and spirometry examination. The spirometer was calibrated before screening was initiated. Because this study was conducted in the community setting, there was no recording of comorbidities at the time of screening. Citizens with evidence of airway obstruction were requested to visit their general practitioner to undergo repeat spirometry and reversibility testing for further diagnosis and eventual treatment. Three months after screening, all citizens were interviewed by telephone to confirm whether the general practitioner was visited (if requested), the general practitioner's action in terms of diagnosis and treatment, and smoking cessation and abstinence. Abstinence from smoking was measured using self-assessment and point prevalence, ie, asking the citizen whether he/she smokes now as opposed to ongoing monitoring for a period of time. To minimize response bias, the interview was not carried out by the same person doing the spirometry. Seven unanswered telephone calls were deemed to be a nonresponse.

Airway obstruction was defined according to GOLD guidelines, ${ }^{1}$ ie, an $\mathrm{FEV}_{1}$ to $\mathrm{FVC}$ ratio below $70 \%$, which is identical to the current guidelines for primary care in Denmark. ${ }^{3,27}$ The indication of severity of a possible diagnosis of COPD was reported using $\mathrm{FEV}_{1}$ in relation to the expected level from normative Danish lung function data. Staging based on screening spirometry was as follows:

- Mild COPD, $\mathrm{FEV}_{1} \geq 80 \%$ of expected

- Moderate COPD, $50 \% \leq \mathrm{FEV}_{1}<80 \%$ of expected

- Severe COPD, $30 \% \leq \mathrm{FEV}_{1}<50 \%$ of expected

- Very severe COPD, $\mathrm{FEV}_{1}<30 \%$ of expected. ${ }^{28}$

Data from the consultation and spirometry investigation were entered by the municipality into a passwordprotected electronic database held by the Danish Technical University. The data recorded were age, gender, height, weight, smoking (status, history, and cessation), respiratory symptoms, and Medical Research Council (MRC) dyspnea scale for grading the degree of a patient's breathlessness relating to daily activities. ${ }^{29} \mathrm{FEV}_{1}$ and $\mathrm{FVC}$ results given by spirometry were also entered into the database. The database calculated whether the person had evidence of airway obstruction and estimated the severity of COPD based on screening spirometry.

The data were analyzed using SPSS version 19.0 (SPSS Inc, Chicago, IL). Checking normal plots and Q-Q plots for normally distributed data descriptive statistics were presented as the mean \pm standard deviation. For comparisons between subjects with evidence of airflow obstruction and those without, between men and women, and between smokers and nonsmokers, the Chi-square test and $t$-test were used depending on the data analyzed and the scale level of these data. Furthermore, correlation testing using the Chi-square test or the $t$-test was performed between specific variables, such as respiratory symptoms and MRC dyspnea scale. A significance level of 5\% was chosen.

All citizens participating in the study provided their informed consent. The Danish Data Protection Agency was notified about the study, because it was covered by a general approval to perform noninterventional studies. The study protocol was also submitted to the local ethics committee and the Danish Medicines Agency for approval. However, being a noninterventional study, both authorities judged that the study did not require their approval.

\section{Results}

In total, 152 citizens in the Municipality of Esbjerg met the inclusion criteria (Table 1). Of the participants, 51\% were active smokers smoking 16 cigarettes per day. All participants reported at least one respiratory symptom, with an average of $2.4 \pm 1.17$ symptoms per participant (data not shown). Dyspnea (70\%), cough (65\%), and sputum (48\%) were the most frequent symptoms reported, whereas fewer subjects reported wheezing (36\%) or a tendency to contract pneumonia (21\%). The MRC dyspnea scale showed an

Table I Demographics and characteristics of I52 citizens

\begin{tabular}{|c|c|c|}
\hline & $\begin{array}{l}\text { Females } \\
(n=76) \\
\text { Mean } \pm \text { SD }\end{array}$ & $\begin{array}{l}\text { Males } \\
(n=76) \\
\text { Mean } \pm \text { SD } \\
\end{array}$ \\
\hline Age (years) & $57 \pm 11.83$ & $60 \pm 10.86$ \\
\hline Body mass index $\left(\mathrm{kg} / \mathrm{m}^{2}\right)^{\mathrm{a}}$ & $25 \pm 4.87$ & $27 \pm 4.22$ \\
\hline Current/former smokers (\%) & $55 / 45$ & $47 / 53$ \\
\hline Pack-years of smokingb & $24 \pm 14.25^{c}$ & $38 \pm 22.02$ \\
\hline Average number of cigarettes per day ${ }^{d}$ & $15 \pm 6.27$ & $20 \pm 11.40$ \\
\hline
\end{tabular}


average score of $1.6 \pm 0.83$, with a daily level of activity between "not troubled by breathlessness except on strenuous exercise" and "short of breath when hurrying or walking up a slight hill". However, some subjects had MRC scales up to severe levels of 3-5, and the level on the MRC scale was correlated with increasing number of respiratory symptoms (Chi-square 69.5, $P<0.001$ ).

\section{Spirometry examinations}

Table 2 shows the results of screening spirometry. The average $\mathrm{FEV}_{1} / \mathrm{FVC}$ ratio was slightly below the definition of airway obstruction (68.8 \pm 10.42$)$. In our sample of 152 subjects, 78 (51.3\%) had evidence of airway obstruction, although the final diagnosis was made by their general practitioner (Figure 1). This was the case for significantly more men $(60 \%)$ than women (42\%) at the municipality screening (Chi-square 5.2, $P=0.02$ ). In addition to these 78 citizens with evidence of airway obstruction, a further 14 participants had evidence of restrictive lung disease. These two groups (61\%) were advised by the municipality to visit their general practitioner for further diagnosis and intervention. Fourteen percent of the 78 citizens with evidence of airway obstruction were assessed to have severe to very severe COPD, whereas the rest were mild to moderate (Figure 1).

\section{Diagnosis of COPD in general practice}

Telephone interviews after 3 months ( $92 \%$ response rate, 12 lost to follow-up) revealed that seven of 10 citizens advised to visit their general practitioner for a diagnosis did so. Among the citizens visiting their general practitioner with evidence of airway obstruction from the municipality screening, $85 \%$ were diagnosed by the general practitioner as having COPD (40 of 47 citizens). Those screened and found to have evidence of moderate (24/25) to very severe (nine citizens with severe to very severe) airway obstruction were also subsequently diagnosed to have COPD by their general practitioner. The uncertainty in municipality screening was related to subjects with mild airway obstruction (46\% disagreement, seven of 13 citizens were diagnosed with COPD). Participants

Table 2 Results of spirometry examination for 152 citizens

\begin{tabular}{lll}
\hline & Mean & SD \\
\hline FEV, (per liter) & 2.43 & 0.79 \\
FVC (per liter) & 3.53 & 1.03 \\
FEV /FVC ratio & 68.76 & 10.42 \\
Expected FEV $_{\text {, }}$ & 3.06 & 0.67 \\
FEV,$\%$ of expected & 79.36 & 18.33 \\
\hline
\end{tabular}

Abbreviations: SD, standard deviation; $\mathrm{FEV}_{1}$, forced expiratory volume in one second; FVC, forced vital capacity.

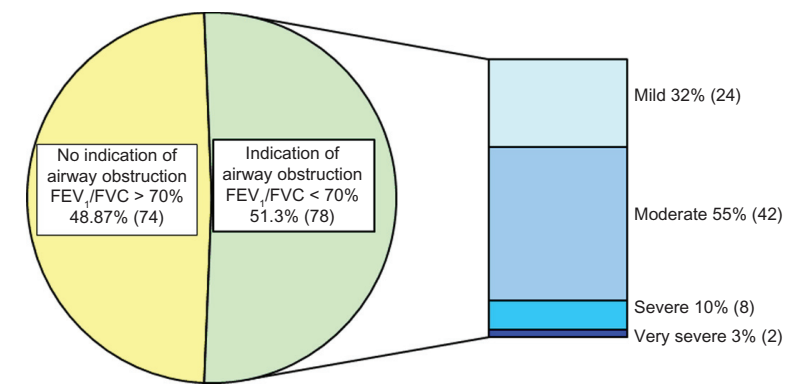

Figure I Airway obstruction and indicated severity of chronic obstructive pulmonary disease based on screening spirometry in 152 citizens. Absolute numbers in brackets. Information on severity of disease was missing for two citizens.

Abbreviations: $\mathrm{FEV}_{1}$, forced expiratory volume in one second; FVC, forced vital capacity.

not visiting their general practitioner were more frequently women, smokers, were smoking significantly fewer cigarettes per day (having a significantly lower score on the MRC dyspnea scale), and had fewer respiratory symptoms, as well as evidence of airway obstruction which was mild or moderate in severity. However, for most characteristics, the differences between those citizens visiting their general practitioner and those who did not were not statistically significant. The mean age and average $\mathrm{FEV}_{1} / \mathrm{FVC}$ ratio were also not found to be different between the two groups.

\section{Treatment initiated for COPD patients}

According to GOLD guidelines, the primary strategy is to reduce the risk factors for COPD, in particular smoking. ${ }^{1}$ The follow-up telephone interview at 3 months after screening found significantly fewer smokers than at the time of screening (self-assessment, point prevalence) among those with an indication of airway obstruction (40\% fewer smokers, Chi-square 24.6, $P<0.001$ ). Participants who continued to smoke after 3 months had a significantly lower $\mathrm{FEV}_{1} / \mathrm{FVC}$ ratio ( $t$-test $2.2 ; P=0.03)$, and their airway obstruction were significantly less severe than those quitting smoking (Chisquare $15.6, P=0.08)$. Furthermore, $57 \%$ of those diagnosed with COPD were undergoing smoking cessation at follow-up compared with only $8 \%$ at the time of screening. The study also identified fewer smokers among those without evidence of airway obstruction (15\% fewer smokers, Chi-square 49.6, $P<0.001)$. Regarding management of stable COPD, $61 \%$ of participants with a diagnosis of COPD had medication prescribed by their GP. Finally, $16 \%$ of the patients diagnosed to have COPD were referred subsequently by their GP to the municipality rehabilitation program. The lower figure for patients undergoing rehabilitation could reflect the short time period of follow-up, as well as the general practitioner's ability to offer this in their practice. 


\section{Discussion}

This study investigated whether early detection of airway obstruction among citizens in the population at risk is feasible and effective at the municipality level in Denmark. The results showed that $50 \%$ of the citizens studied have indications of airway obstruction with most of them (85\%) ending up with a final diagnosis of COPD, indicating that early detection of COPD in the municipalities is feasible, worthwhile, and effective. Only 1-2 of every ten citizens screened with evidence of airway obstruction were false-positive, and these false positives were nearly all suspected to have mild airway obstruction. Furthermore, the number of smokers quitting, as well as the frequency of smoking cessation, was increased 3 months after screening for airway obstruction.

This was also the case for a smaller proportion of citizens with no evidence of airway obstruction (15\%), which confirms the importance of awareness at the time of screening concerning smoking and the risk of having COPD. These results are in accordance with the COPD guidelines recommending smoking cessation as the primary intervention. ${ }^{1}$

General practice is an important arena for early detection of COPD. The participants could have visited their GP. However, they did not do so. Municipality screening made the risk factors for COPD and the possibility of examination visible to citizens; it was more anonymous and noncommitted compared with visiting their own general practitioner. The reasons why a small proportion of subjects did not visit their general practitioner after municipality screening included being unaware of the need for further diagnosis by the general practitioner, having not had the time to do so yet, taking the initiative to quit smoking by themselves, and sensing a lack of interest by their general practitioner concerning COPD and smoking cessation. In addition to the minority of participants not understanding the seriousness of the screening result and need for further action, the municipalities are an important ancillary arena for early detection of COPD that attracts additional persons at risk of having COPD. This is in accordance with the recommendation made by the governmental prevention commission..$^{25}$

As already mentioned, the different guidelines and recommendations do not recommend spirometric screening of adults for COPD in the community. ${ }^{1,16,17}$ On the other hand, reviews of spirometry show its importance. ${ }^{19}$ Although performed on a small scale, the present study has shown that spirometric screening in the community is feasible and effective. Despite some of the recommendations against screening with spirometry, eg, from the US Preventive
Services Task Force ${ }^{16}$ community screening in the present study focused on a population at risk who had recognized respiratory symptoms and were smokers or former smokers, and therefore not healthy or asymptomatic adults. This follows the official Danish guidelines issued by the National Board of Health. ${ }^{3}$

The finding that more than $50 \%$ of subjects had evidence of airway obstruction in the present study is higher than rates reported by other researchers. ${ }^{20-24}$ One major reason for this is probably the self-referral method used for recruitment in the present study, with newspaper advertisements showing the risk group indicators for COPD according to the Danish National Board of Health. Many of the citizens visiting the Healthcare Center for examination may have been aware that they were likely to have lung disease. However, they were still not diagnosed with COPD before the visit and therefore screening was relevant to them. Second, the possibility of remaining anonymous during spirometric screening when undertaken in the municipality may have been another explanation. Finally, it has to be remembered that the proportion of subjects ending up with a diagnosis of COPD after visiting their general practitioner was lower (44\%).

\section{Study limitations}

The present study had some limitations. First, the sample size was small. However, this was a pilot study to investigate the feasibility and potential success of screening for airway obstruction at the community level. Second, recruitment for screening was based upon self-referral, with a risk of selection bias towards those with the disease of interest. However, those identified were undiagnosed beforehand and at risk of suffering from COPD, which is why screening was deemed relevant, and investigating prevalence was not part of the aim of this study. Third, the data on diagnosis and treatment in general practice were patient-reported and not information supplied directly by general practitioners. Patient-reporting may have limitations in terms of recall bias and uncertainty, but was considered to be the only feasible way to obtain the data. Fourth, guidelines suggest that the final diagnosis in general practice should include reversibility testing with bronchodilators and repeat spirometry. ${ }^{1}$ We have to assume that this was the case in general practice, but because this was not recorded, there is some uncertainty. However, new data have been reported using the same inclusion criteria for screening in primary care in Denmark as in the present study, but with repeated reversibility testing. ${ }^{30}$ Of 4049 screened patients, $23.1 \%$ had airway obstruction, with $21.7 \%$ 
confirmed to have COPD after reversibility testing. ${ }^{30}$ These data indicate that only a small number of patients initially identified using spirometry alone do not have COPD after reversibility testing. Furthermore, Danish guidelines from the National Board of Health only recommend use of spirometry for the early detection of COPD. ${ }^{3}$ Fifth, the current international guidelines question the use of fixed ratios and $\mathrm{FEV}_{1} /$ FVC, resulting in misclassification. ${ }^{1,16}$ However, due to the noninterventional nature of this study, the current Danish guidelines as to classification had to be followed in the present study. ${ }^{3,27}$ It is expected that these national guidelines will be updated to reflect the new 2011 GOLD update.

\section{Conclusion}

Together with early detection of COPD in general practice, early detection of airway obstruction in defined risk populations in Danish municipalities seems feasible and effective in identifying new undetected COPD patients. The results of the present study provide some indication of the potential of using spirometry at the municipality level for early detection of COPD. On the other hand, the results of the study cannot be used to support community screening of COPD in healthy and/or asymptomatic adults, as argued against by US Preventive Services Task Force. ${ }^{16}$

Our results could be of interest to other countries, given the feasibility and potential shown with community screening of a population at risk. The potential in other countries will of course depend upon the eventual guidelines for early detection of COPD, as well as the expected proportion of undiagnosed COPD patients in the country, which is regarded as rather high in Denmark. ${ }^{2,3}$ Additional research is needed in larger samples of people at risk of COPD and in more municipalities to see whether the successful results found for community screening in the present study can be confirmed. This research could also include investigation of whether early intervention improves morbidity and mortality and saves costs for the municipality, health care sector, and society.

\section{Disclosure}

Pfizer Denmark Aps and Boehringer Ingelheim funded the project database and assisted in the analyses of the project. CBA, JD, and PBP are employees of Pfizer Denmark Aps. TRJ, MS, LBS, and RBHJ are employees of the Municipality of Esbjerg. The results of this study were presented at the 5th International Primary Care Respiratory Group World Conference in Toronto, Canada, June 2-5, 2010.

\section{References}

1. Global initiative for chronic obstructive lung disease. Global strategy for the Diagnosis, Management, and Prevention of chronic obstructive pulmonary disease. Updated 2010. Available from: www.goldcopd.org. Accessed October 18, 2011.

2. Løkke A, Fabricius PG, Vestbo J, Marott JL, Lange P. Prevalence of chronic obstructive pulmonary disease in Copenhagen. Results from The Copenhagen City Heart Study. Ugeskr Laeger. 2007;169: 3956-3960. Danish.

3. Chronic obstructive pulmonary disease. Recommendations for early identification, follow-up, treatment and rehabilitation. [Kronisk obstruktiv lungesygdom. Anbefalinger for tidlig opsporing, opfølgning, behandling og rehabilitering]. Copenhagen, Denmark: The National Board of Health; 2007. [Danish.]

4. Data from the National Hospital Register. [Landspatientregistret]. Copenhagen, Denmark: The National Board of Health; 2009. [Danish.]

5. Death Cause Register. [Dødsårsagsregistret, Tal og analyse]. Copenhagen, Denmark: The National Board of Health; 2009. [Danish.]

6. Bilde L, Rud Svenning A, Dollerup J, Baekke Borgeskov H, Lange P. The cost of treating patients with COPD in Denmark - a population study of COPD patients compared with non-COPD controls. Respir Med. 2007;101:539-546.

7. Hilleman DE, Dewan N, Malesker M, Friedman M. Pharmacoeconomic evaluation of COPD. Chest. 2000;118:1278-1285.

8. Miravitlles M, Murio C, Guerrero T, Gisbert R. Costs of chronic bronchitis and COPD: a 1-year follow-up study. Chest. 2003;123: 784-791.

9. Koleva D, Motterlini N, Banfi P, Garattini L. Study Group BIC. Healthcare costs of COPD in Italian referral centres: a prospective study. Respir Med. 2007;101:2312-2320.

10. Balmes J, Becklake M, Blanc P, et al. Environmental and Occupational Health Assembly, American Thoracic Society. American Thoracic Society Statement. Occupational contribution to the burden of airway disease. Am J Respir Care Med. 2003;167:787-797.

11. Hnizdo E, Sullivan PA, Bang KM, Wagner G. Association between chronic obstructive pulmonary disease and employment by industry and occupation in the US population: A study of data from the Third National Health and Nutrition Examination Survey. Am J Epidemiol. 2002;156:738-746.

12. Trupin L, Earnest G, San Pedro M, et al. The occupational burden of chronic obstructive pulmonary disease. Eur Respir J. 2003;22: 462-469.

13. Lange P, Andersen KK, Munch E, et al. Quality of COPD care in hospital outpatient clinics in Denmark: The KOLIBRI study. Respir Med. 2009;103:1657-1662.

14. Lange P, Rasmussen FV, Borgeskov H, et al. The quality of COPD care in general practice in Denmark: the KVASIMODO study. Prim Care Respir J. 2007;16:174-181.

15. Grann O, Godtfredsen NS, Dollerup J, et al. Chronic obstructive pulmonary disease (COPD) rehabilitation at Health Care Centres in municipalities in Denmark - the KOALA project. Prim Care Resp J. 2010;19:A5.

16. US Preventive Services Task Force. Screening for chronic obstructive pulmonary disease using spirometry: US Preventive Services Task Force Recommendation Statement. Ann Intern Med. 2008;148:529-534.

17. Miller MR, Hankinson J, Brusasco V, et al. Standardisation of spirometry. ATS/ERS Task Force. Eur Respir J. 2005;26:319-338.

18. Lacasse Y, Goldstein R, Lasserson TJ, Martin S. Pulmonary rehabilitation for chronic obstructive pulmonary disease. Available from: http://www.cochrane.org/reviews/en/ab003793.html. Accessed January 5, 2012.

19. Soriano JB, Zielinski J, Price D. Screening for and early detection of chronic obstructive pulmonary disease. Lancet. 2009;374:721-732.

20. Ulrik CS, Løkke A, Dahl R, et al. Early detection of COPD in general practice. Int J Chron Obstruct Pulmon Dis. 2011;6:123-127. 
21. Løkke A, Christensen LB, Fuglsang C. Walk-in spirometry pilot project for discovering of early chronic obstructive pulmonary disease. $U g e s k r$ Laeger. 2009;171:3083-3088. Danish.

22. Tinkelman DG, Price D, Nordyke RJ, Halbert RJ. COPD screening efforts in primary care: what is the yield? Prim Care Respir J. 2007; 16:41-48.

23. Hill K, Goldstein RS, Guyatt GH, et al. Prevalence and underdiagnosis of chronic obstructive pulmonary disease among patients at risk in primary care. CMAJ. 2010;182:673-678.

24. Zielinski J, Bednarek M; The Know the Age of Your Lung Study Group. Early detection of COPD in a high-risk population using spirometric screening. Chest. 2001;119:731-736.

25. We need to live longer and healthier. Recommendations for an improved prevention by the Governmental Prevention Commission. [Vi skal leve loengere og sundere. Forebyggelseskommissionens anbefalinger til en styrket forebyggende indsats, Betcenkning 1506]. Copenhagen, Denmark: Governmental Prevention Commission (Forebyggelseskommissionen); 2009. [Danish.]

26. Wilt TJ, Niewoehner D, Kim C, et al. Use of spirometry for case finding, diagnosis, and management of chronic obstructive pulmonary disease (COPD). Evid Rep Technol Assess (Summ). 2005;121:1-7.
27. Dansk Selskab for Almen Medicin (DSAM). KOL i almen praksis. Diagnostik, behandling, opfølgning, rehabilitering. The Danish College of General Practitioners: COPD in General Practice, 2008. Available from: http://www.dsam.dk/flx/kliniske_vejledninger/kol_i_almen_praksis/. Accessed November 28, 2011.

28. National Collaborating Centre for Chronic Conditions. Chronic obstructive pulmonary disease. National clinical guideline on management of chronic obstructive pulmonary disease in adults in primary and secondary care. Thorax. 2004;59 Suppl:1-232.

29. Fletcher CM, Elmes PC, Fairbairn MB, Wood CH. The significance of respiratory symptoms and the diagnosis of chronic bronchitis in a working population. $\mathrm{Br}$ Med J. 1959;2:257-266.

30. Ulrik CS, Løkke A, Dahl R, et al. Early diagnosis of COPD in a highrisk population using spirometric screening in general practice. Poster P4152 presented at the European Respiratory Society conference, Amsterdam, The Netherlands, September 24-28, 2011.
International Journal of COPD

\section{Publish your work in this journal}

The International Journal of COPD is an international, peer-reviewed journal of therapeutics and pharmacology focusing on concise rapid reporting of clinical studies and reviews in COPD. Special focus is given to the pathophysiological processes underlying the disease, intervention programs, patient focused education, and self management protocols.

\section{Dovepress}

This journal is indexed on PubMed Central, MedLine and CAS. The manuscript management system is completely online and includes a very quick and fair peer-review system, which is all easy to use. Visit http://www.dovepress.com/testimonials.php to read real quotes from published authors. 